\title{
Discoidin domain receptor 1 is associated with poor prognosis of non-small cell lung carcinomas
}

\author{
SUN HO YANG ${ }^{1 *}$, HYUN AH BAEK ${ }^{1 *}$, HO JIN LEE ${ }^{1}$, HO SUNG PARK ${ }^{1,3}$, \\ KYU YUN JANG ${ }^{1,3}$, MYOUNG JAE KANG ${ }^{1,3}$, DONG GEUN LEE ${ }^{1,3}$, YONG CHUL LEE ${ }^{2}$, \\ WOO SUNG MOON ${ }^{1,3,4}$ and MYOUNG JA CHUNG ${ }^{1,3}$ \\ ${ }^{1}$ Department of Pathology, ${ }^{2}$ Internal Medicine, Chonbuk National University Medical School; \\ ${ }^{3}$ Institute for Medical Science; ${ }^{4}$ Diabetes Research Center, Jeonju 561-180, Korea
}

Received March 11,2010; Accepted May 5, 2010

DOI: 10.3892/or_00000861

\begin{abstract}
Discoidin domain receptors (DDRs) are a novel class of receptor tyrosine kinases that bind to several collagens and facilitate cell adhesion. DDR1 is involved in cancer invasion. However, very limited data are available on the aspect of clinical significance of DDR1 expression in cancer. The aim of this study was to investigate prognostic impact of DDR1 expression in non-small cell lung carcinoma (NSCLC). Tumor tissues from 171 NSCLC, including 86 squamous cell carcinomas, 69 adenocarcinomas, and 16 pure bronchioloalveolar carcinomas (BAC), were analyzed for expression of DDR1 using immunohistochemical staining. In addition, two lung adenocarcinoma cell lines (A549, H358) were transfected with two isoforms of DDR1, DDR1a and DDR $1 b$, and then migration and invasion assays were carried out. DDR1 was expressed in 6 of 16 BAC (38\%) and 95 of 155 invasive $\operatorname{NSCLC}(61 \%, \mathrm{p}=0.065)$. DDR1 up-regulation tend to be more frequently observed in invasive adenocarcinoma (64\%) compared to DDR1 expression in BAC $(38 \%)(\mathrm{p}=0.056)$. In invasive NSCLC, DDR1 expression was significantly correlated with lymph node metastasis $(\mathrm{p}=0.001)$. Overexpression of DDR1 in lung cancer cells resulted in a significant increase of cell motility and invasiveness $(p<0.001)$ and the interaction of DDR1 with collagen facilitates the invasiveness of NSCLC cells. DDR1 overexpression produced an activation of MMP-9 in H358 cells. In conclusion, these findings indicate that up-regulation of DDR 1 may contribute to the progression and poor prognosis of NSCLC and this effect may be associated with increased invasiveness.
\end{abstract}

Correspondence to: Dr Myoung Ja Chung or Dr Woo Sung Moon, Department of Pathology, Chonbuk National University Medical School, San 2-20 Keumam-Dong Dukjin-gu, Jeonju 561-180, Korea

E-mail: mjchung@jbnu.ac.kr; wsmoon@jbnu.ac.kr

*Contributed equally

Key words: discoidin domain receptor 1, prognosis, carcinoma, lung, metastasis

\section{Introduction}

Invasion and metastasis are very important prognostic factors for carcinomas and a major cause of cancer-related morbidity and mortality. Interaction between tumor cells and the extracellular matrix (ECM) is an early and important step in invasion and metastasis.

Discoidin domain receptor (DDR) is a receptor tyrosine kinase with an N-terminal domain that is homologous to the Dictyostelium discoideum protein discoidin I (1). DDR and tyrosine kinase are known to be key regulators of cellular morphogenesis, differentiation, proliferation and death $(2,3)$. There are two types of DDR, DDR1 and DDR2, which are characterized by an approximately 155 -amino acid discoidin homology domain in the extracellular region of the protein (4). DDRs bind to several collagens and the presence of the discoidin domain in DDR is thought to be essential for collagen-binding. DDR1 is primarily expressed in epithelial cells in the lung, kidney, colon and brain and it is stimulated by collagen types I, II, III, IV, V, VIII and XI. Whereas DDR2 is expressed in interstitial cells in kidney, skin and skeletal and heart muscle and it is activated mainly by fibrillar collagens, type I and III (1,5-7). Human DDRI gene is located on chromosome $6 \mathrm{p} 21.3$ among several HLA genes belonging to the telomeric region of the major histocompatibility complex $(8,9)$. DDR1 consists of a characteristic discoidin homology domain, stalk region, transmembrane region, juxtamembrane region and kinase domain (10). The discoidin homology domain is characterized by an approximately 155 -amino acid in the extracellular region of the protein. Thus far, five isoforms of DDR1 (DDR1a-1e) have been cloned as a result of alternative splicing in the cytoplasmic region $(1,11)$. Among the five isoforms of DDR1, the DDR1b protein is the predominant isoform expressed during embryogenesis, whereas the a-isoform is commonly found in several human mammary carcinoma cell lines (9).

DDR1 expression is increased in multiple human cancers, including astrocytoma (7), prostate cancer (12), and ovarian carcinoma $(13,14)$. Previously, we have reported that overexpression of DDR1 increases the migration and invasion of hepatocellular carcinoma (HCC) cells (15). Although there have been reports that DDR1 is involved in cancer invasion 
Table I. Correlation between clinicopathological parameters and expression of DDR1 in non-small cell lung carcinoma.

\begin{tabular}{|c|c|c|c|c|}
\hline \multirow{2}{*}{$\begin{array}{l}\text { Clinicopathological } \\
\text { parameters }\end{array}$} & \multirow{2}{*}{$\begin{array}{l}\text { No. of } \\
\text { cases }\end{array}$} & \multicolumn{3}{|c|}{ DDR1 } \\
\hline & & - & + & P-value \\
\hline Age & & & & 0.070 \\
\hline$<69$ & 71 & 22 & 49 & \\
\hline$\geq 69$ & 84 & 38 & 46 & \\
\hline Sex & & & & 0.129 \\
\hline Male & 89 & 39 & 50 & \\
\hline Female & 66 & 21 & 45 & \\
\hline Histologic type & & & & 0.571 \\
\hline Squamous carcinoma & 86 & 35 & 51 & \\
\hline Adenocarcinoma & 69 & 25 & 44 & \\
\hline Histologic grade & & & & 0.829 \\
\hline Well, Moderate & 120 & 47 & 73 & \\
\hline Poor & 35 & 13 & 22 & \\
\hline Size $(\mathrm{cm})$ & & & & 0.680 \\
\hline$\leq 2$ & 31 & 13 & 18 & \\
\hline$>2$ & 124 & 47 & 77 & \\
\hline T stage & & & & 0.619 \\
\hline $\mathrm{T} 1, \mathrm{~T} 2$ & 127 & 48 & 79 & \\
\hline $\mathrm{T} 3, \mathrm{~T} 4$ & 28 & 12 & 16 & \\
\hline Lymph node metastasis & & & & 0.001 \\
\hline Negative & 86 & 43 & 43 & \\
\hline Positive & 69 & 17 & 52 & \\
\hline Pleural invasion & & & & 0.177 \\
\hline Negative & 135 & 55 & 80 & \\
\hline Positive & 20 & 5 & 15 & \\
\hline Invasiveness & & & & 0.056 \\
\hline $\mathrm{BAC}$ & 16 & 10 & 6 & \\
\hline Invasive AD & 69 & 25 & 44 & \\
\hline
\end{tabular}

BAC, bronchioloalveolar carcinoma; AD, adenocarcinoma.

and migration, very limited data are available on the role of DDR1 as a prognostic indicator in human cancer (12). In this study, we examined effect of DDR 1 overexpression in invasiveness of cancer cells and the prognostic impact of DDR1 expression in NSCLC.

\section{Materials and methods}

Patients. Tissues from 171 non-small cell lung carcinoma (NSCLC) patients who underwent surgery at the Department of Chest Surgery, Chonbuk National University Hospital between January 1999 and December 2006 were selected for this study. The inclusion criteria for this study were: a diagnosis of primary NSCLC, and complete clinicopathological data for review. The tumors included 86 cases of invasive squamous cell carcinoma (SCC), 69 cases of invasive adenocarcinoma (AC), and 16 cases of bronchioloalveolar carcinoma (BAC). Pathological staging was reviewed based on the tumor, node, and metastasis staging system of the American Joint Committee on Cancer (16). Clinical information was obtained through a computerized database of the tumor registry and clinical information of invasive NSCLCs is summarized in Table I. All of the BACs were non-mucinous type. The mean tumor size was $0.94 \mathrm{~cm}$ $(0.6-1.9 \mathrm{~cm})$ and none of the BACs had lymph node metastasis and pleural invasion. Hematoxylin and eosinstained slides of NSCLCs were reviewed for confirmation of histopathological diagnosis and selection of adequate specimens for immunohistochemical analysis. Histologic typing was performed according to the histological classification of lung cancer by the World Health Organization (17). This study was approved by the Human Ethics Committee of Chonbuk National University Medical School. Informed consent was provided according to the Declaration of Helsinki.

Immunohistochemistry. Immunohistochemistry was performed using $3.0 \mathrm{~mm}$ tumor cores for tissue microarray (TMA). One core per case was arrayed. Thirty cores of normal lung tissue served as control group. Sections $(5 \mu \mathrm{m})$ were cut from a tissue microarray block and deparaffinized in xylene and rehydrated in graded alcohols. Immunohistochemical staining was done with the Dako Envision system, which uses dextran polymers conjugated with horseradish peroxidase (Dako, Carpinteria, CA, USA). Antigen retrieval was achieved by incubation of tissue sections in boiling 10 (mol/l citrate buffer ( $\mathrm{pH} 6.0$ ) for $10 \mathrm{~min}$ in a microwave oven prior to incubation at $4{ }^{\circ} \mathrm{C}$ overnight with primary antibodies against DDR1 (sc-532, raised in rabbit against an epitope mapping to the C-terminus of DDR1, Santa Cruz Biotechnology, Santa Cruz, CA, USA). After incubation with the appropriate biotin-conjugated secondary antibody and subsequently with a streptavidin solution, color development was done using 3-amino-9-ethylcarbazole (AEC) (Lab Vision, CA) as a chromogen. Appropriate negative controls, consisting of tissue sections of each case processed without the addition of primary antibody, were prepared. All of the immunostained sections were evaluated by two pathologists (M.J.C. and H.S.P.) who had no knowledge of the clinical status of the patients. Tumors were considered to be positive for DDR1 when positive reactivity was observed in $>25 \%$ of the tumor cells with stronger intensity compared to normal lung epithelial cells. The DDR1 polyclonal antibody (C-20) detects both DDR1a and DDR1b.

Cell culture. Five human NSCLC cell lines (A549, H358, H23, $\mathrm{H} 460$, and H520) were purchased from the American Type Culture Collection (Manassas, VA) and cultured according to the manufacturer's instructions. The cells were maintained in RPMI supplemented with penicillin and streptomycin (100 U/ml)) with $10 \%$ fetal bovine serum (Gibco-BRL, Gaithersburg, MD), and were grown at $37^{\circ} \mathrm{C}$ in a humidified, $5 \% \mathrm{CO}_{2}$ atmosphere. After $24 \mathrm{~h}$, cultures of $40-60 \%$ confluent cells were used. 
Cell transfection. The $3.1 \mathrm{~kb}$ EcoRI-XhoI fragment of DDR1a cDNA and the $3.55 \mathrm{~kb}$ EcoRI-BamH1 fragment of DDR1b cDNA were cloned to the plasmid pRK5 (BD Biosciences, Franklin Lakes, NJ). A549 and H358 cells were transiently transfected with the plasmids harboring DDR1a, DDR1b, or the vector only (mock-transduced) using Lipofectamine (Invitrogen, Carlsbad, CA). Briefly, one day before transfection, cells were plated in a $60-\mathrm{mm}$ dish with antibiotic-free serum. At the time of transfection, cell confluence was $50 \%$ and the medium was changed to serum free medium. The DNA for DDR1a and DDR1b (2 $\mu$, each) was diluted in $100 \mu 1$ of RPMI. After $15 \mu 1$ lipofectin had been diluted to $100 \mu \mathrm{l}$ with RPMI, it was left to stand at room temperature for $45 \mathrm{~min}$. The diluted DNA was combined with diluted Lipofectamine. Subsequently, the mixture was incubated for $15 \mathrm{~min}$ at room temperature. This mixture was added to the cells removed from the growth medium. The cells were incubated at $37^{\circ} \mathrm{C}$ in a $\mathrm{CO}_{2}$ incubator for $18 \mathrm{~h}$. After $44 \mathrm{~h}$, cells were harvested and expression of the transfected gene was evaluated by Western blotting.

Western blotting. Whole cell lysates were prepared and the level of DDR1 expression was examined by Western blotting. Anti-DDR1 antibody (C-20, Santa Cruz Biotechnology) was used. Blots were developed using corresponding HRPconjugated secondary antibody, followed by chemiluminescence detection (Amersham Bioscience, Buckinghamshire, UK). A luminescent image analyzer (LAS-3000, Fuji Photo Film, Tokyo, Japan) was used to quantify the data.

Migration assay. Migration assays were done using an HTS Transwell-24 system with an $8-\mu \mathrm{m}$ pore size (Corning, NY). Cells $\left(5 \times 10^{4}\right)$ overexpressing DDR1a, DDR1b and vector alone (Mock) were suspended in serum-free RPMI medium and placed in the upper chambers in triplicate. The upper and lower chambers were separated by a polyvinylpyrrolidonefree polycarbonate membrane and RPMI with $10 \%$ FBS added to the lower chamber as the chemoattractant in one group (group A). To evaluate the effect of collagen type I as the chemoattractant, we added to the other group (group B), $10 \mu \mathrm{g} / \mathrm{ml}$ collagen type I (Sigma, St. Louis, MO) in medium containing $10 \%$ FBS to the lower chamber. After incubation for $72 \mathrm{~h}$, the cells on the upper surface of the filter were wiped with a cotton swab. Cells on the lower surface of the filters were fixed and stained for $10 \mathrm{~min}$ using Diff-Quik solution (Dade Behring, Deerfield, IL). For each replicate, the cells that migrated to the lower surface of the filter were counted under a light microscope in five randomly selected fields (x200) per well.

Invasion assay. Invasion assays were done using 24-transwell BD BioCoat Matrigel Invasion Chambers with an $8-\mu \mathrm{m}$ pore size (BD Biosciences, San Jose, CA). RPMI supplemented with $15 \%$ FBS and collagen type I (Sigma) was placed in the lower chamber. We then placed $\left(1 \times 10^{5}\right)$ cells overexpressing DDR1a, DDR1b and vector alone (Mock) supplemented with 5\% FBS in the upper chambers in triplicate. Cells were allowed to invade through the matrigel at $37^{\circ} \mathrm{C}$ for $48 \mathrm{~h}$ and stained with Diff-Quik solution (Dade Behring). For each replicate, the cells that migrated to the lower surface of the filter were counted under a light microscope in five randomly selected fields (x100) per well.

Zymography. The conditioned media from the H358 and A549 cells were stimulated with collagen type I $(30 \mu \mathrm{g} / \mathrm{ml})$ and collected after $16 \mathrm{~h}$. The conditioned medium $(20 \mu \mathrm{l})$ was mixed with $5 \mu 1$ of a SDS sample buffer and left to stand at room temperature for $10 \mathrm{~min}$. The mixtures were electrophoresed on $7.5 \%$ PAGE containing $1 \mathrm{mg} / \mathrm{ml}$ gelatin (Sigma). After electrophoresis, the gels were washed twice for 30 min with $2.5 \%$ Triton $\mathrm{X}-100$, incubated overnight at $37^{\circ} \mathrm{C}$ in the developing buffer $(50 \mathrm{mM}$ Tris- $\mathrm{HCl}, 200 \mathrm{mM}$ $\mathrm{NaCl}, 5 \mathrm{mM} \mathrm{CaCl} 2,0.02 \%$ Brij 35, pH 7.5). The gels were then stained for $30 \mathrm{~min}$ with $30 \%$ methanol $/ 10 \%$ acetic acid containing $0.5 \%$ Coomassie Brilliant Blue R-250, and destained in the same solution without dye.

Statistical analysis. The statistical significance of the data was analyzed using the SPSS software package, version 15.0 (Seoul, Korea). P-values were determined via $\chi^{2}$ tests or one-way ANOVA. Overall survival (OS) was calculated as the time from diagnosis to the date of death or last contact. Univariate and multivariate Cox regression analysis were performed to estimate the impact of clinicopathological factors and expression of each marker on OS. A p-value $\leq 0.05$ was considered as statistically significant.

\section{Results}

DDRl expression correlated with lymph node metastasis of non-small cell lung cancer. DDR1 expression in NSCLC tissues was evaluated using immunohistochemistry. A total of 171 tissues from NSCLC patients were available for DDR1 analysis. DDR1 was detected in the cytoplasmic membrane and cytoplasm of cancer cells and infiltrated lymphocytes in tumor stroma (Fig. 1). In normal lung, DDR1 was consistently non-staining in normal epithelium. In some cases, DDR1 positivity was found in normal epithelium with weak intensity. DDR1 was overexpressed in 6 of 16 BAC (38\%), 95 of 155 invasive NSCLC (61\%), 51 of 86 invasive squamous cell carcinoma (59\%), and 44 of 69 invasive adenocarcinoma (64\%). DDR1 up-regulation tend to be more frequently observed in invasive adenocarcinoma compared to DDR 1 expression in BAC $(\mathrm{p}=0.056)$. Correlations between clinicopathological parameters of invasive NSCLC and expression of DDR1 are summarized in Table I. DDR1 expression was significantly correlated with lymph node metastasis $(\mathrm{p}=0.001)$. Other clinicopathological parameters were not found to be correlated with DDR1 expression.

Expression of DDRI in NSCLC correlates with reduced overall survival. Univariate and multivariate analysis for OS were performed for 155 invasive NSCLC patients with complete information for all variables (Table II). The mean follow-up duration of patients was 33.3 months (range, 4-80 months). High $\mathrm{T}$ stage, the presence of lymph node metastasis, tumor $>2 \mathrm{~cm}$, and DDR1 expression were associated with a significantly shorter OS by univariate analysis $(\mathrm{p}<0.001, \mathrm{p}<0.001, \mathrm{p}=0.008, \mathrm{p}=0.041$, respectively). Poorly differentiated carcinoma tended to be associated with shorter 


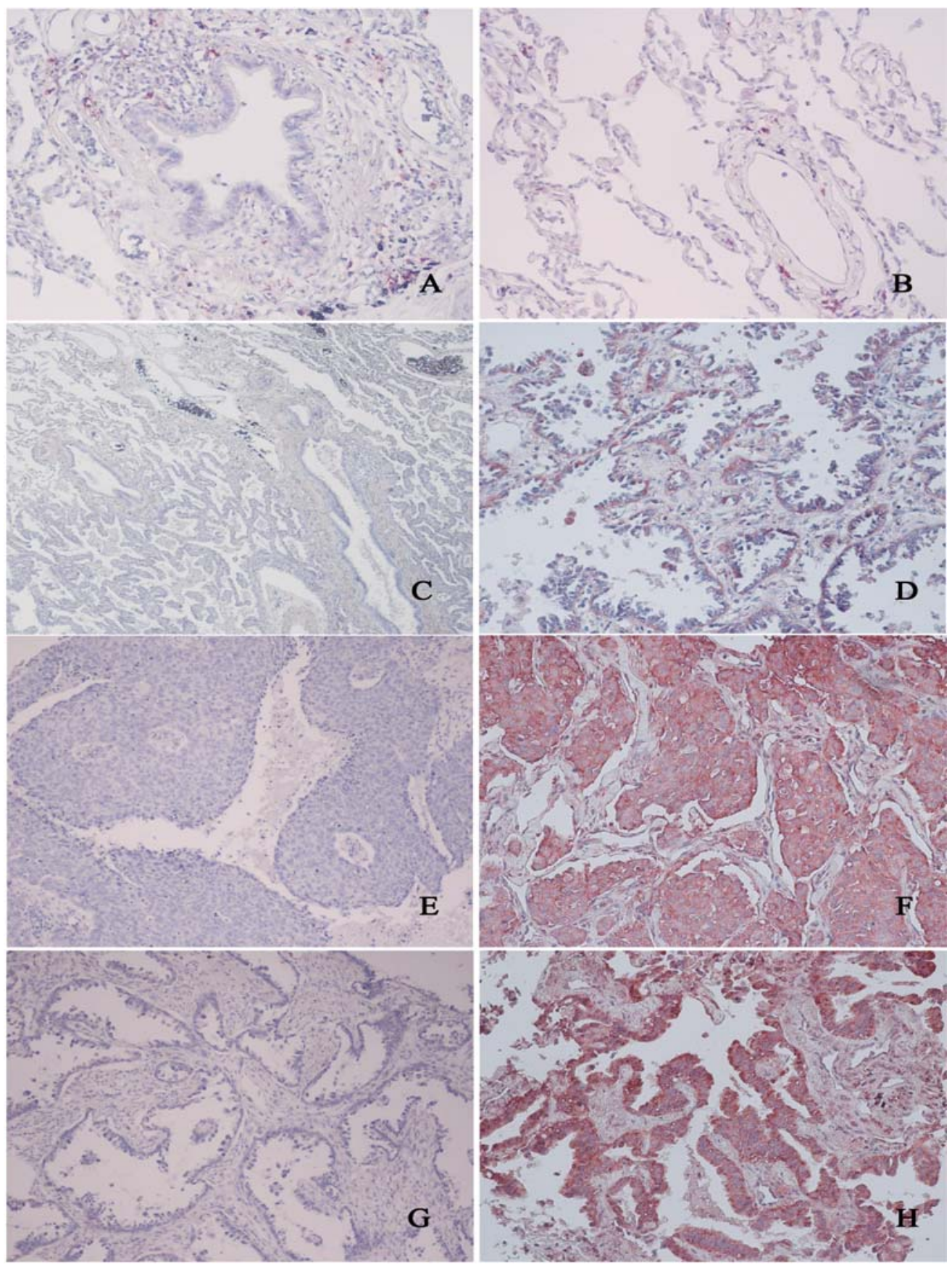

Figure 1. Immunoreactivity for DDR1 in normal (A and B), bronchioloalveolar carcinoma (C and D), adenocarcinoma (E and F) and squamous cell carcinoma $(\mathrm{G}$ and $\mathrm{H})$. Immunohistochemical stains for DDR1 shows membranous and cytosolic staining in cancer cells.

OS $(p=0.059)$ by univariate analysis. Variables considered in the multivariate analysis were the age, tumor size, histological grade, T stage, lymph node metastasis, pleural invasion, and DDR1 expression. From the multivariate analysis, tumor $\mathrm{T}$ stage and lymph node metastasis were independent prognostic factors significantly associated with OS ( $\mathrm{p}=0.015$, $\mathrm{p}=0.003$, respectively). Tumor $>2 \mathrm{~cm}$ tended to be associated with shorter OS $(\mathrm{p}=0.081)$ by multivariate analysis.

Overexpression of DDRIa and DDRIb stimulates lung cancer cell migration and invasion in vitro. In order to examine the role of DDR1 in NSCLC progression, a DDR1 overexpression model was developed by transiently trans- fecting cells with DDR1a and DDR1b cDNA in a plasmid vector. The cels were lysed and probed with an anti-DDR1 antibody. The expression level of the DDR1 protein in the five NSCLC cell lines was determined by Western blotting. A low level of expression was detected in the five cell lines (Fig. 2A) and two cell lines (A549 and H358) were transfected with DDR 1 to determine the effects of DDR 1 on migration and invasion in the NSCLC cell lines. As shown in Fig. 2B, the transfection was satisfactory and the DDR1 protein was overexpressed by the transfected cells.

To investigate migration of DDR1a or DDR1b overexpressing lung cancer cells, migration assays were performed using an HTS Transwell-24 system with an $8-\mu \mathrm{m}$ 
Table II. Cox regression analysis for overall survival in non-small cell lung carcinoma patients.

\begin{tabular}{|c|c|c|c|c|c|c|c|}
\hline \multirow[b]{2}{*}{ Characteristics } & \multirow{2}{*}{$\begin{array}{c}\text { No. of } \\
\text { cases }\end{array}$} & \multicolumn{3}{|c|}{ Univariate analysis } & \multicolumn{3}{|c|}{ Multivariate analysis } \\
\hline & & HR & $95 \% \mathrm{CI}$ & P-value & $\mathrm{HR}$ & $95 \% \mathrm{CI}$ & P-value \\
\hline \multicolumn{8}{|l|}{ Age } \\
\hline$<69$ & 71 & 1.441 & $0.812-2.558$ & 0.212 & 0.984 & $0.539-10796$ & 0.958 \\
\hline$\geq 69$ & 84 & & & & & & \\
\hline \multicolumn{8}{|l|}{ Histologic grade } \\
\hline Low & 120 & 0.555 & $0.301-1.024$ & 0.059 & 0.742 & $0.388-1.421$ & 0.742 \\
\hline High & 35 & & & & & & \\
\hline \multicolumn{8}{|l|}{ Tumor size (cm) } \\
\hline$\leq 2$ & 31 & 0.205 & $0.063-0.665$ & 0.008 & 0.343 & $0.103-1.143$ & 0.081 \\
\hline$>2$ & 124 & & & & & & \\
\hline \multicolumn{8}{|l|}{ T stage } \\
\hline 1,2 & 127 & 0.283 & $0.157-0.510$ & $<0.001$ & 0.467 & $0.253-0.867$ & 0.015 \\
\hline 3,4 & 28 & & & & & & \\
\hline \multicolumn{8}{|l|}{ LN metastasis } \\
\hline Negative & 86 & 0.243 & $0.123-0.478$ & $<0.001$ & 0.347 & $0.171-0.705$ & 0.003 \\
\hline Positive & 69 & & & & & & \\
\hline \multicolumn{8}{|l|}{ Pleural invasion } \\
\hline Negative & 135 & 0.718 & $0.320-1.609$ & 0.420 & 0.708 & $0.313-1.600$ & 0.407 \\
\hline Positive & 20 & & & & & & \\
\hline \multicolumn{8}{|l|}{ DDR1 } \\
\hline Negative & 60 & 0.529 & $0.287-0.974$ & 0.041 & 0.600 & $0.313-1.149$ & 0.124 \\
\hline Positive & 95 & & & & & & \\
\hline
\end{tabular}

LN, lymph node; LV, lymphatic vessel; DDR1, discoidin domain receptor 1; HR, hazard ratio.

A

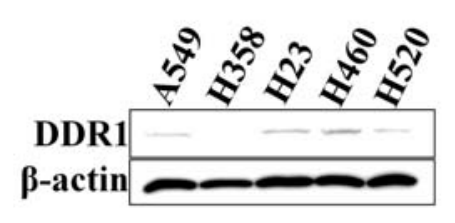

B

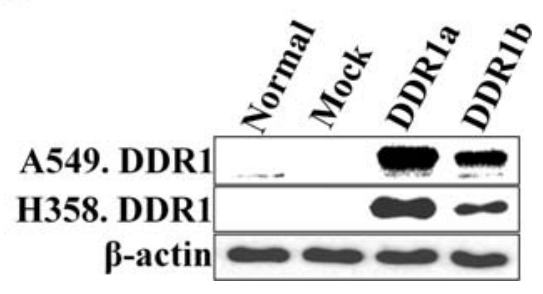

Figure 2. Expression of DDR1 in the five NSCLC cell lines (A). In the Western blotting, a low level of expression was identified in five NSCLC cell lines. Immunoblot analysis of DDR1 after transfection with DDR1a or DDR1b in the A549 and H358 cell line (B). The transiently transfected tumor cells show overexpression of the DDR1 protein.

pore size (Corning, NY). In group A (no collagen type I added in the lower chamber), overexpression of DDR1a resulted in a 1.69-fold increase in the number of migrating cells in the A549 cells ( $\mathrm{p}=0.027$ ) and a 2.15 -fold increase in the H358 cells ( $\mathrm{p}=0.009)$ compared with MOCK (Table III). There was an increase in the number of migrating cells after DDR1b-overexpression, but this was not significant in either A549 or H358 cells ( $>0.05)$. The chemotactic effect of collagen to DDR1 overexpressing cells was assessed by adding collagen type $\mathrm{I}$ in the lower chamber. In group B (collagen type I added in the lower chamber), the number of migrating cells was 4.06 and 7.39 times higher in DDR1aoverexpresssing A549 and H358 cells than the MOCK cells, respectively $(\mathrm{p}<0.001)$. The number of migrating cells was 3.20 times higher in DDR1b-overexpresssing A549 cells than the MOCK cells $(\mathrm{p}<0.001)$ (Fig. 3, Table III). DDR1b-over- 
Table III. Effect of the overexpression of DDR1a or DDR1b in migration and invasion of lung cancer cells.

\begin{tabular}{|c|c|c|c|c|c|c|}
\hline & \multicolumn{4}{|c|}{ Migration } & \multicolumn{2}{|c|}{ Invasion } \\
\hline & Group A & P-value & Group B & $\mathrm{P}$-value & & P-value \\
\hline A549. Mock & $305.00 \pm 24.19$ & & $829.50 \pm 42.66$ & & $516.00 \pm 46.19$ & \\
\hline A549. DDR1a & $515.67 \pm 55.81$ & 0.027 & $3369.50 \pm 278.00$ & 0.000 & $1639.00 \pm 22.52$ & 0.000 \\
\hline A549. DDR1b & $370.33 \pm 38.13$ & 0.540 & $2656.25 \pm 180.60$ & 0.000 & $1275.34 \pm 37.67$ & 0.000 \\
\hline H358. Mock & $97.75 \pm 5.08$ & & $64.83 \pm 5.93$ & & $263.3 \pm 41.84$ & \\
\hline H358. DDR1a & $210 \pm 35.56$ & 0.009 & $479.17 \pm 26.61$ & 0.000 & $647.3 \pm 151.59$ & 0.029 \\
\hline H358. DDR1b & $150 \pm 6.03$ & 0.129 & $135.3 \pm 52.53$ & 0.079 & $410.5 \pm 51.53$ & 0.318 \\
\hline
\end{tabular}

Group A, no collagen type I added in the lower chamber; group B, collagen type I added in the lower chamber.
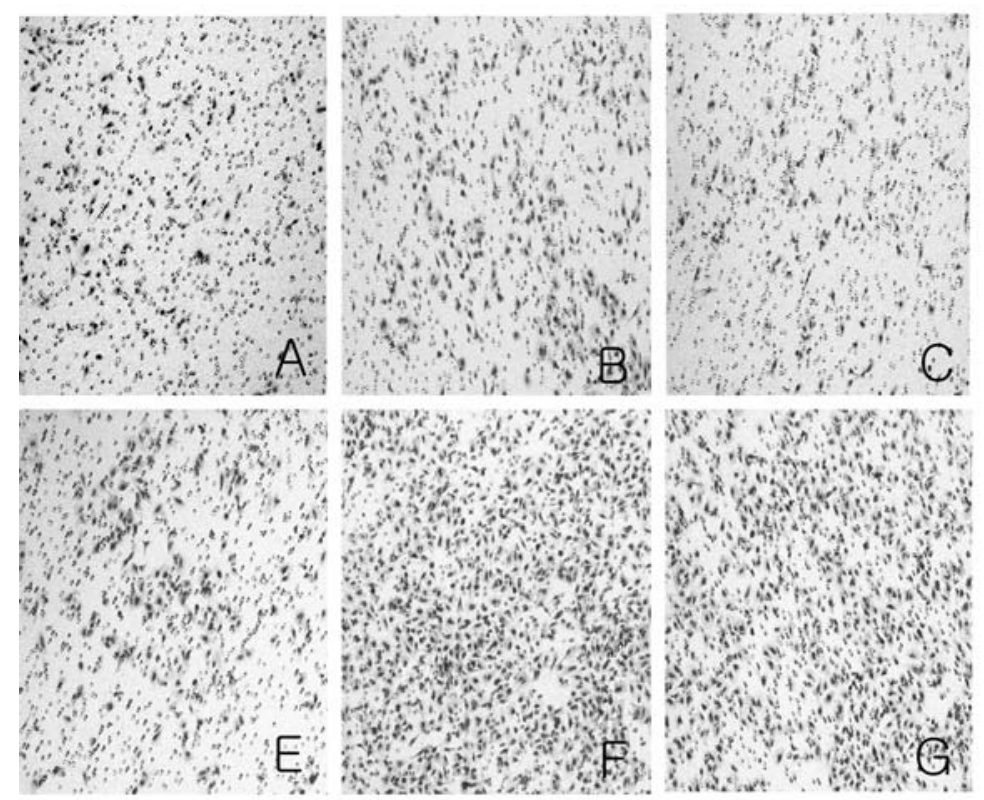

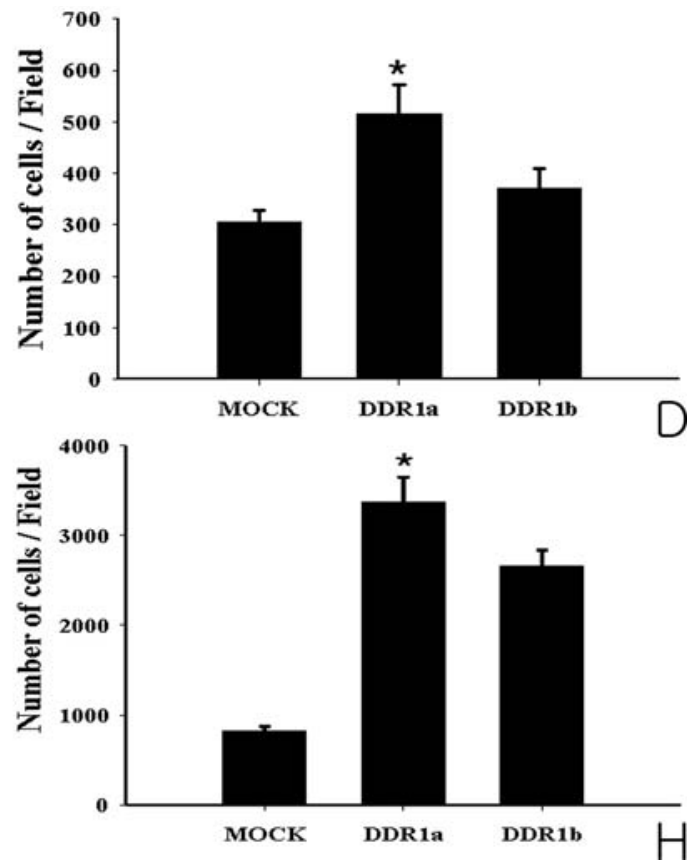

Figure 3. Migration assay for DDR1a or DDR1b-overexpressing A549 cells in group A (A-D) and group B (E-H). The number of migrating cells was significantly higher in DDR1a-overexpresssing cells in group A (no stimulation of collagen) and significantly higher in DDR1a- and DDR1b-overexpressing cells in group B (with stimulation of collagen) than in MOCK cells. The number of migrating cells significantly increased with stimulation of collagen compared with cells without collagen stimulation $(\mathrm{p}<0.001)$. The assays were performed in triplicate on three separate occasions. Asterisks indicate a significant difference $(\mathrm{p}<0.05)$ from the mean value for the control (Mock cells). (A and E) Mock; (B and F) DDR1a; (C and G) DDR1b.

expressing H358 cells showed a 2.1-fold increase in the number of migrating cells compared with that of MOCK cells, but the difference was not significant $(\mathrm{p}=0.079)$. In DDR1a-overexpressing cells, the number of migrating cells was significantly higher in both cell lines when collagen type I was added in the lower chamber compared with the group not supplemented with collagen $(\mathrm{p}<0.001)$ (Table III). In DDR1b-overexpressing cells, the number of migrating A549 cells was 7.18 times increased by addition of collagen $(p<0.001)$. These results suggest that collagen type I stimulates DDR1-mediated cell migration.

Next we performed an assay for invasion of NSCLC cells through Matrigel. The number of invading cells was 3.18 and 2.5 times higher in DDR1a-overexpressing H358 and A549 cells than in MOCK cells, respectively (Fig. 4, Table III) $(p<0.05)$. In DDR1b-overexpressing cells, the number of invading A549 cells was 2.47 times higher than the MOCK cells $(\mathrm{p}<0.001)$.

DDRla- and DDRIb-overexpressing NSCLC cells show activation of MMP-9. In this study, the interaction of DDR1 with collagen facilitated the invasiveness of NSCLC cells. DDR 1 is reported to be associated with matrix metalloproteinase (MMP)-2 and MMP-9 activation, which plays an important role in the invasiveness of cancer. Therefore, we examined the relationship between DDR1 overexpression and MMP-2/-9 activation in H358 and A549 cells. Zymography was used to determine whether the invasion of 

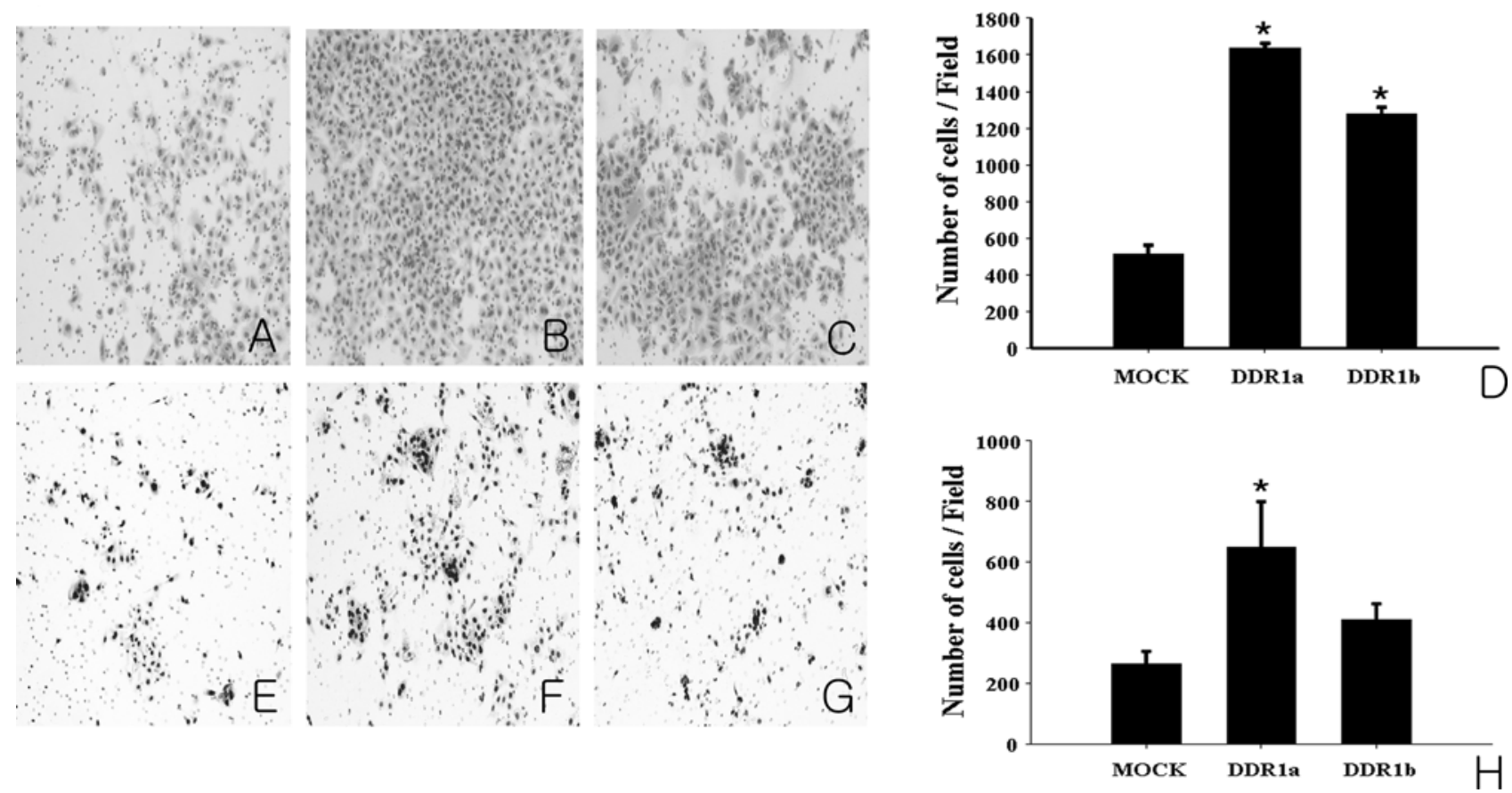

Figure 4. Invasion assay for DDR1a or DDR1b-overexpressing A549 (A-D) and H358 (E-H) cells. The number of invading cells was significantly higher in DDR1a-overexpressing cells than MOCK cells. In DDR1b-overexpressing cells, the number of invading cells was significantly higher in A549 cells than MOCK cells. The assays were done in triplicate one three separate occasions. Asterisk indicates a significant difference $(\mathrm{p}<0.05)$ from the mean value for the control (Mock cells). (A and E) Mock; (B and F) DDR1a; (C and G) DDR1b.

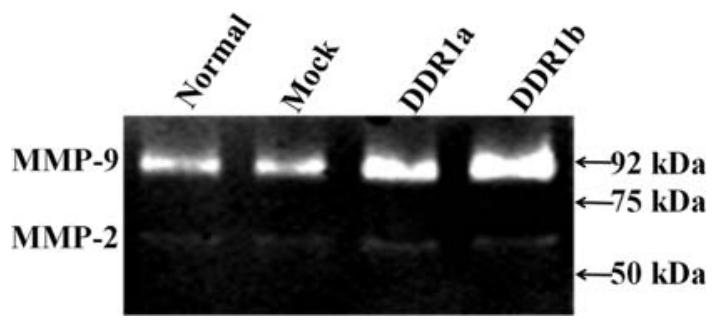

Figure 5. Zymography for DDR1a- and DDR1b-overexpressing H358 cells. Expression of MMP-9 was higher in the DDR1a- and DDR1boverexpressing H358 cells than in the control. Activation of MMP-2 was unclear.

DDR1-overexpressing cells was mediated by the activation of MMP-2 and -9. In the H358 cells, DDR1a- and DDR1boverexpression produced an activation of MMP-9 (Fig. 5). We found no significant activation of MMP-2 in H358 and MMP-2 and MMP-9 in A549 cells.

\section{Discussion}

Lung cancer is the leading cause of cancer-associated deaths worldwide and has one of the poorest prognosis among all cancer types. NSCLC accounts for up to $80 \%$ of lung cancer cases, and the 5-year survival rate of patients with NSCLC, which is less than $15 \%$, remains among the lowest of all major human cancers. Thus, there is a need for newer and more effective targeted therapies. Identifying reliable markers predictive of clinical outcomes would be desirable in order to guide clinicians in selecting new treatment options and monitoring treatment responses of patients.
In this study, we examined the prognostic impact of DDR1 in NSCLC and the role of DDR1 in migration and invasion of lung adenocarcinoma cell lines to investigate a role for DDR1 as a novel biomarker in NSCLC. Our results demonstrated the following: i) DDR1 is up-regulated in NSCLC as compared to DDR1 expression in normal lung tissue; ii) DDR1 expression tended to be associated with invasiveness of adenocarcinoma; iii) DDR1 expression is significantly correlated with lymph node metastasis in NSCLC; iv) expression of DDR1 in NSCLC correlates with reduced overall survival by univariate analysis; v) overexpression of DDR1a and DDR1b stimulates lung cancer cell migration and invasion in vitro; vi) DDR1a- and DDR1boverexpressing H358 cells show activation of MMP-9. With these results, we suggest that DDR1 expression is a clinically significant negative prognostic indicator for NSCLC patients.

Accumulating evidence suggests that DDR1 is involved in cancer invasiveness. High levels of DDR1 were reported for invasive tumors of the breast, esophagus, ovary, prostate, and lung (12-14,18-20). DDR expression was stronger in cancer than normal tissue and DDR expression positively correlated with the proliferative activity of carcinoma cells (19). Cancer cells overexpressing DDR1 display enhanced invasion and migration $(7,15)$. In prostate carcinoma, DDR1 promotes cancer development through enhancing cancer cell survival and invasion and high DDR1 expression is associated with short hormone resistance interval and progression (12). In the present study, we found that DDR1 expression is up-regulated in NSCLC compared to DDR1 expression in normal lung and it tended to be associated with invasiveness of adenocarcinona. It was significantly correlated with lymph node metastasis and short OS by univariate Cox 
regression analysis. NSCLC cells (H358 and A549) overexpressing DDR1 increased their motility and invasiveness. The interaction of DDR 1 with collagen facilitated the invasiveness of NSCLC cells. We suggest that up-regulation of DDR1 promotes tumor motility and invasiveness and then it resulted in tumor progression and metastasis.

Matrix metalloproteinases (MMPs), a family of zincdependent endopeptidases, degrade the basement membrane and extracellular matrix, facilitating cell migration, tumor invasion, and metastasis $(21,22)$. Among the MMPs, MMP-2 and MMP-9 are considered especially important in the malignant behavior of tumor cells $(23,24)$. Recently, several reports showed that DDR1 can function as an inducer of MMP $(7,12,15)$. MMP-2 is activated in DDR1a overexpressing glioma cells and inhibition of MMP activity suppressed DDR1a stimulated cell invasion (7). DDR1a and DDR1b overexpression resulted in an increase of MMP-2 and MMP-9 in hepatocellular carcinoma cell lines (15). Shimada et al showed that overexpression of DDR1 made the cells more invasive through the up-regulation of MMP-9 in a prostate cancer cell line (12). In the present study, we found that H358 cells with DDR1a and DDR1b overexpression induced up-regulation of MMP-9. We suggest that MMP activation is involved in increased invasiveness of DDR1-overexpressing cells and the type of MMP on DDR1-mediated invasiveness may be dependent on the cell type. However, A549 cells with DDR1 overexpression did not show MMP-9 activation. Further study on DDR-mediated signals on invasion will be needed. Up-regulation of $\mathrm{N}$ cadherin has a profound effect on the ability of tumor cells to invade and metastasize and DDR1 induce collagen Imediated up-regulation of $\mathrm{N}$-cadherin in pancreatic cancer cells $(25,26)$. Downstream targets of activated DDR1, such as $\mathrm{N}$-cadherin, will be valuable in the understanding of how DDR1 promotes NSCLC progression.

We found that the DDR1a overexpressing cells showed stronger effect in migration and invasion compared with those of DDR1b overexpressing cells. These results are similar to those reported by Park et al and Kamohara et al $(15,27)$. Although the mechanism of the difference between the invasiveness of DDR 1a and DDR 1b is unknown, structural differences and divergent signaling between DDR 1a and DDR1b have been suggested as a reason $(28,29)$. Structurally, the DDR1a and DDR1b isoforms differ from each other by an in-frame insertion of a $111 \mathrm{bp}$ segment that codes for an additional 37-amino acid peptide in the proline-rich juxtamembranous region (1). The juxtamembranous region of the a-isoform binds to fibroblast growth factor receptor substrate-2 and appears to be unique in its ability to trigger the migration and pseudopod extension of leukocytes (27).

In conclusion, DDR 1 is significantly up-regulated in invasive NSCLC and it was significantly correlated with lymph node metastasis, pleural invasion and shorter survival. Overexpression of DDR1 in lung adenocarcinoma cells resulted in significantly increased cell motility and invasiveness and activation of MMP-9. These findings indicate that up-regulation of DDR1 may contribute to the progression and poor prognosis of NSCLC and this effect may be associated with increased invasiveness.

\section{Acknowledgements}

This study was supported by the Ministry of Science and Technology (MoST)/Korea Science and Engineering Foundation (KOSEF) through the Diabetes Research at Chonbuk National University (R13-2008-005-0000-0) and by a grant of the Korea Healthcare technology R\&D project, Ministry for Health, Welfare and Family Affairs, Republic of Korea (A084144).

\section{References}

1. Vogel W: Discoidin domain receptors: structural relations and functional implications. FASEB J 13: 77-82, 1999.

2. Curat CA and Vogel WF: Discoidin domain receptor 1 controls growth and adhesion of mesangial cells. J Am Soc Nephrol 13: 2648-2656, 2002.

3. Ongusaha PP, Kim JI, Fang L, et al: p53 induction and activation of DDR1 kinase counteract p53-mediated apoptosis and influence p53 regulation through a positive feedback loop. EMBO J 22: 1289-1301, 2003.

4. Alves F, Vogel W, Mossie K, Millauer B, Höfler H and Ullrich A: Distinct structural characteristics of discoidin I subfamily receptor tyrosine kinases and complementary expression in human cancer. Oncogene 10: 609-618, 1995

5. Shrivastava A, Radziejewski C, Campbell E, et al: An orphan receptor tyrosine kinase family whose members serve as nonintegrin collagen receptors. Mol Cell 1: 25-34, 1997.

6. Vogel W, Gish GD, Alves F and Pawson T: The discoidin domain receptor tyrosine kinases are activated by collagen. Mol Cell 1: 13-23, 1997

7. Ram R, Lorente G, Nikolich K, Urfer R, Foehr E and Nagavarapu U: Discoidin domain receptor-1a (DDR1a) promotes glioma cell invasion and adhesion in association with matrix metalloproteinase-2. J Neurooncol 76: 239-248, 2006.

8. Edelhoff S, Sweetser DA and Disteche CM: Mapping of the NEP receptor tyrosine kinase gene to human chromosome 6p21.3 and mouse chromosome 17C. Genomics 25: 309-311, 1995.

9. Perez JL, Shen X, Finkernagel S, et al: Identification and chromosomal mapping of a receptor tyrosine kinase with a putative phospholipid binding sequence in its ectodomain. Oncogene 9: 211-219, 1994.

10. Playford MP, Butler RJ, Wang XC, Katso RM, Cooke IE and Ganesan TS: The genomic structure of discoidin receptor tyrosine kinase. Genome Res 6: 620-627, 1996.

11. Alves F, Saupe S, Ledwon M, Schaub F, Hiddemann W and Vogel WF: Identification of two novel, kinase-deficient variants of discoidin domain receptor 1: differential expression in human colon cancer cell lines. FASEB J 15: 1321-1323, 2001.

12. Shimada K, Nakamura M, Ishida E, et al: Prostate cancer antigen-1 contributes to cell survival and invasion though discoidin receptor 1 in human prostate cancer. Cancer Sci 99: 39-45, 2008.

13. Laval S, Butler R, Shelling AN, Hanby AM, Poulsom R and Ganesan TS: Isolation and characterization of an epithelialspecific receptor tyrosine kinase from an ovarian cancer cell line. Cell Growth Differ 5: 1173-1183, 1994.

14. Heinzelmann-Schwarz VA, Gardiner-Garden M, Henshall SM, et al: Overexpression of the cell adhesion molecules DDR1, Claudin 3, and Ep-CAM in metaplastic ovarian epithelium and ovarian cancer. Clin Cancer Res 10: 4427-4436, 2004.

15. Park HS, Kim KR, Lee HJ, et al: Overexpression of discoidin domain receptor 1 increases the migration and invasion of hepatocellular carcinoma cells in association with matrix metalloproteinase. Oncol Rep 18: 1435-1441, 2007.

16. Greene F, Page D and Fleming I: AJCC Cancer Staging Manual. In: Lung. (6th edition). Springer-Verlag, New York, pp167-176, 2002 .

17. Travis WD, Brambilla E, Muller-Hermeling HK and Harris CC: World Health Organization classification tumors of the lung, pleura, thymus and heart. In: Tumors of the Lung. IARC Press, Lyon, pp9-124, 2004.

18. Ford CE, Lau SK, Zhu CQ, Andersson T, Tsao MS and Vogel WF: Expression and mutation analysis of the discoidin domain receptors 1 and 2 in non-small cell lung carcinoma. Br J Cancer 96: 808-814, 2007. 
19. Nemoto T, Ohashi K, Akashi T, Johnson JD and Hirokawa K: Overexpression of protein tyrosine kinases in human esophageal cancer. Pathobiology 65: 195-203, 1997.

20. Barker KT, Martindale JE, Mitchell PJ, et al: Expression patterns of the novel receptor-like tyrosine kinase, DDR, in human breast tumours. Oncogene 10: 569-575, 1995.

21. Curran S and Murray GI: Matrix metalloproteinases: molecular aspects of their roles in tumour invasion and metastasis. Eur J Cancer 36: 1621-1630, 2000

22. Johansson N, Ahonen M and Kähäri VM: Matrix metalloproteinases in tumor invasion. Cell Mol Life Sci 57: 5-15, 2000.

23. Sakamoto Y, Mafune K, Mori M, et al: Overexpression of MMP-9 correlates with growth of small hepatocellular carcinoma. Int J Oncol 17: 237-243, 2000.

24. Nomura H, Sato H, Seiki M, Mai M and Okada Y: Expression of membrane-type matrix metalloproteinase in human gastric carcinomas. Cancer Res 55: 3263-3266, 1995.

25. Shintani, Y, Hollingsworth MA, Wheelock MJ and Johnson KR: Collagen I promotes metastasis in pancreatic cancer by activating c-Jun $\mathrm{NH}_{2}$-terminal kinase 1 and up-regulating $\mathrm{N}$-Cadherin expression. Cancer Res 66: 11745-11753, 2006.
26. Shintani Y, Fukumoto Y, Chaika N, Svoboda R, Wheelock MJ and Johnson KR: Collagen I-mediated up-regulation of Ncadherin requires cooperative signals from integrins and discoidin domain receptor 1. J Cell Biol 180: 1277-1289, 2008.

27. Kamohara H, Yamashiro S, Galligan C and Yoshimura T: Discoidin domain receptor 1 isoform- $\alpha$ (DDR1alpha) promotes migration of leukocytes in three-dimensional collagen lattices. FASEB J 15: 2724-2726, 2001.

28. Matsuyama W, Wang L, Farrar WL, Faure M and Yoshimura T: Activation of discoidin domain receptor 1 isoform $b$ with collagen up-regulates chemokine production in human macrophages: role of p38 mitogen-activated protein kinase and NF-kappa B. J Immunol 172: 2332-2340, 2004.

29. Matsuyama W, Kamohara H, Galligan C, Faure M and Yoshimura T: Interaction of discoidin domain receptor 1 isoform b (DDR1b) with collagen activates p38 mitogenactivated protein kinase and promotes differentiation of macrophages. FASEB J 17: 1286-1288, 2003. 